\title{
Results From the Republic of Slovenia's 2016 Report Card on Physical Activity for Children and Youth
}

\author{
Vedrana Sember, Gregor Starc, Gregor Jurak, Mojca Golobič, Marjeta Kovač, \\ Poljanka Pavletič Samardžija, and Shawnda A. Morrison
}

\begin{abstract}
Background: This is the first assessment of the Republic of Slovenia's efforts to synthesize and report physical activity (PA) standards for children and youth following the Active Healthy Kids Global Alliance grading system model. Methods: The Republic of Slovenia Report Card relies on research findings published in peer-reviewed journals, data compiled from national databases, and government initiatives which have been monitoring physical fitness standards in schools for the past 34 years (SLOfit and ACDSi). The Report Card initiative has been jointly coordinated by the University of Primorska and the University of Ljubljana. A Research Work Group consisting of 12 representatives from various aspects of Slovenia's public, private, and government sectors convened to evaluate evidence and assign grades for each PA indicator. Results: Grades ( $A$, highest, to $F$, lowest; $I N C$, incomplete) for Slovenia are as follows: Overall Physical Activity $(A-)$, Organized Sport Participation $(B-)$, Active Play $(D)$, Active Transportation $(C)$, Sedentary Behaviors $(B+)$, Family and Peers (INC), Schools $(A)$, Community and the Built Environment $(I N C)$, and Government $(B+)$. Conclusion: This inclusive PA report indicates that overall physical activity minutes remain high in Slovenian children and youth; however, more research is needed to determine the effects of family life, peer influences, and the built environment on active play behaviors.
\end{abstract}

Keywords: evidence-based research, physical fitness, policy

The Republic of Slovenia is a small, central European nation within the European Union with a population of 2,064,188 and a gross domestic product of $€ 35,416$ million. ${ }^{1}$ It has diverse topography and climates, ranging from Mediterranean along the short Adriatic coastline, to the mountainous regions of the Julian Alps in the north, to flat agricultural lands to the east. It celebrated 25 years of independence in 2016. Every April the majority of Slovenian children and youth aged 6 to 19 years are included in nation-wide, school-based physical fitness measurements as part of an initiative called SLOfit (the Sport Educational Chart program). SLOfit is obligatory for all Slovenian primary and secondary schools across the country. For more than 30 years, this system has been allowing teachers and researchers access to high-quality, standardized data on physical fitness and education monitored on an annual basis. Based on evidence of declining physical fitness from the SLOfit data, Slovenia introduced a health-oriented physical activity (PA) intervention program called Healthy Lifestyle (HLS) in the school year 2010-2011, offering children 2 optional, additional hours of PA per week. ${ }^{2}$ HLS is considered part of a school's regular extracurricular health-oriented PA program. This project currently includes more than $30 \%$ of the entire primary-school population. Before this initiative, Slovenian kids had been experiencing negative trends in motor and physical fitness for over 2 decades, but since 2011, physical fitness in 6- to 14-year-olds has been steadily improving. ${ }^{2}$

Sember and Morrison are with Applied Kinesiology, University of Primorska, Slovenia. Starc, Jurak, and Kovač are with the Faculty of Sport, University of Ljubljana, Slovenia. Golobic is with the Biotechnical Faculty, University of Ljubljana, Slovenia. Samardžija is with the Olympic Committee of Slovenia, Association of Sports Federations, Ljubljana, Slovenia. Morrison (shawnda.morrison@upr.si) is corresponding author.
Since the SLOfit system provides reliable, longitudinal information on the physical fitness of Slovenian schoolkids (in part due to uniform school-based PA policies), the Republic of Slovenia is participating in the Global Matrix 2.0 to determine the current state of PA behaviors of children and youth outside the current schoolbased system. Currently, overall children's PA has not been available in a single report, nor have other investigations $\mathrm{s}^{3-7}$ assessed PA following an established grading system used by the Active Healthy Kids Global Alliance (www.activehealthykids.org). Therefore, this Report Card provides comprehensive insight from the best available evidence on several indicators related to PA levels, including policy, environmental issues, and social trends from across the country.

The purpose of the present article is to summarize the results of the Republic of Slovenia's first annual Report Card, and to communicate these findings to a wider international community. A second motivation is to identify areas of research that are currently lacking or underdeveloped in Slovenia, and to determine how PA opportunities may be improved for children and youth across the country. Sources used to create this Report Card include the SLOfit database (1989-2015), ${ }^{8}$ the 2013 and 2014 ACDSi (Analysis of Children's Development in Slovenia Survey),, 10 and various academic and nonacademic (eg, government reports) sources.

\section{Methods}

The development of the Republic of Slovenia Report Card was coordinated by representatives from the Faculty of Applied Kinesiology, University of Primorska (Koper) and the Faculty of Sport, University of Ljubljana. During a period from March to July 2015, a Slovenian representative was invited by the Active Healthy Kids Global Alliance to participate in the Global Matrix 2.0, and began the process of creating a national Report Card. A research work 
group (RWG) was assembled, represented by 4 faculties from 2 Slovenian Universities: 1) the Faculty of Mathematics, Natural Sciences, and Information Technologies, University of Primorska; and 2) Faculty of Sport, 3) Medical Faculty; and 4) Biotechnical Faculty, all from the University of Ljubljana. Representation was also secured from the Slovenian Olympic Committee, an elementary school board Headmaster, and Slovenia's National Institute for Public Health. Thus, the RWG consisted of a diverse, 12-member team, following the suggestions of the Active Healthy Kids Global Alliance International Template and modeled on similar international cards, in particular, the Canadian Report Card released by Active Healthy Kids Canada. ${ }^{11}$

Development of the Report Card occurred over approximately 12 months, including establishing cooperation between research institutions, assembly of experts from backgrounds related to child PA, data sources identification, data collection and synthesis, and, finally, a critical assessment of the data amassed to identify and grade all 9 PA indicators. Indicators included: 1) Overall Physical Activity, 2) Organized Sport Participation, 3) Active Play, 4) Active Transport, 5) Sedentary Behavior, 6) Family and Peers, 7) Schools, 8) Community and the Built Environment, and 9) Government Strategies and Investments. Feedback from the country mentor on Report Card development was obtained in December 2015, when program coordinators met to identify and evaluate overall sources of health indicators. In January 2016, the RWG team met to discuss literature, data sources, and future literature review strategies. RWG meetings followed approximately once per month from January 2016, during which the team analyzed existing data and identified weaknesses in literature and data sources. Team members continued collecting data sources for 2 categories, Family and Peers and Active Play. In March 2016, the RWG met twice for extended grade evaluation meetings.

To assess the health and behavioral situation of Slovenian children and youth, data were drawn from completed and ongoing Slovenian government projects related to core indicators and benchmarks (Table 1). The most comprehensive source of PA data in children and youth was the ACDSi 2013 and 2014 study, ${ }^{9,10}$ which includes information on self-reported and parent-reported PA behaviors in 6- to 19-year-olds $(n=5422)$ from the CLASS ${ }^{12}$ and SHAPES questionnaires. ${ }^{13}$ Core indicators were graded with letters based on the deliberations of the RWG. According to these standards, grades were defined when the percentage of children meeting established benchmarks fell between the following: $A$ $=81 \%$ to $100 \% ; B=61 \%$ to $80 \% ; C=41 \%$ to $60 \% ; D=21 \%$ to $40 \% ; F=0 \%$ to $20 \%$; INC = incomplete data. Criteria for assigning grades was based on the Canadian report and other previously published national reports. ${ }^{11,14}$ In assessing these grades, the RWG considered the sample size of the data and compared representative databases to objectively measured PA data, when available. When assigning the grades, nationally representative data took precedence. When sizable differences between variables existed (eg, age, sex, geographic region), separate grades are provided in-text, and the letter grade was a weighted average between the 2 groups.

\section{Results}

The 2016 Slovenia Report Card is the first consolidated assessment of PA in children and youth for the country which follows the Active Healthy Kids Global Alliance grading system. Grades are summarized in Table 2 . The cover story depicts children playing outdoors, with the slogan "Is Slovenia moving healthy within nature?" (Slovenian language: Slovenija, Gibaj zdravo z naravo; Figure 1), a reference to the fact that Slovenia belongs to one of the most forested countries in Europe, with many national parks, yet PA data indicate children are less physically active on weekends and holidays, despite the excellent potential for enjoying all of Slovenia's natural environments.

\section{Overall Physical Activity: A-}

According to the most recent ACDSi data, 97\% of boys and 95\% girls (ages: 6 to $11 \mathrm{y}$ ) are meeting WHO recommendations for daily PA.9 These data are in accordance with objectively measured data from a sample of 11-year-olds from Ljubljana, which confirms that almost all children meet WHO recommendations. ${ }^{15}$ Combined data of younger (age 6-11 y) and older age groups (12-18 y) find that $86 \%$ of boys and $76 \%$ of girls meet PA guidelines. When stratified by activity on weekdays, $82 \%$ of boys and $72 \%$ of girls (all ages) meet PA recommendations, respectively. On weekends, this percentage remained relatively high ( $81 \%$ boys, $72 \%$ girls meeting recommendation guidelines). The overall physical activity indicator was graded $A$-.

\section{Organized Sport Participation: B-}

There is no centralized registry of sport practice or participation in organized clubs for children and youth outside of the school system in Slovenia. Although some organized sport data do exist, there are issues with reporting consistency throughout the different legislative branches. Therefore, based on school records from an ACDSi nationally representative sample, $60 \%$ of boys and $47 \%$ of girls aged 6 to 19 years report being engaged in extracurricular sport or clubs. The difference between boys and girls who are involved in organized sport practice in primary school is small $(68 \%$ and $63 \%$ ), but as children enter secondary level, these numbers drop to $49 \%$ in boys and $23 \%$ in girls, respectively. The organized sport participation indicator was graded $B$ -

\section{Active Play: $D$}

Data for this indicator were derived from questions querying parents on how much active play occurs in the home (eg, playing in the house yard, roller-skating outside, playing catch, riding bike, etc.) from the CLASS questionnaire ${ }^{12}$ used in the ACDSi study. ${ }^{9}$ According to these results, on school days only $16 \%$ of boys and $19 \%$ girls aged 6 to 11 years play actively for more than 2 hours per day $(\sim F)$; on weekends this figure increased to $57 \%$ and $59 \%$ of boys and girls $(\sim C)$, respectively. Overall, combined school day and weekend outdoor play data reveal that $29 \%$ of boys and $30 \%$ of girls play outside more than 2 hours per day. The active play indicator was graded $D$.

\section{Active Transportation: $\mathbf{C}$}

The percentage of children and youth who use active transportation to get to and from school has been queried in 31 schools across Slovenia (Kolesarski letopis, 2014). A nationally representative dataset found that the number of children and youth using an active method of transport to/from school was bike 3\%; walk $26 \%(\sim D)$. In the national capital Ljubljana, the proportion of active transport was higher: bike 6\%; walk 52\% ( C). Interestingly, when children were asked which mode of transportation they would prefer to take to school, kids answered with the highest proportion wishing 


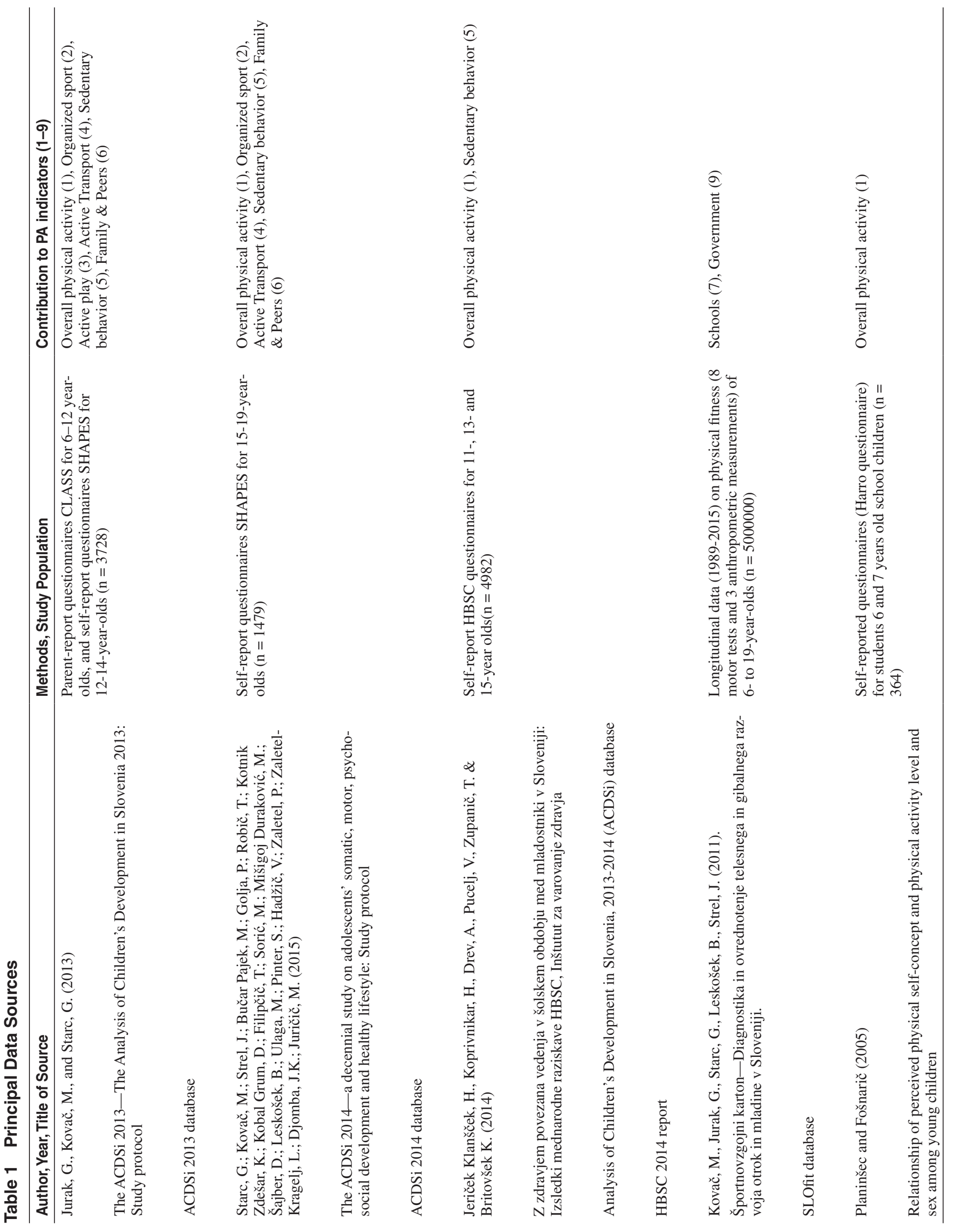




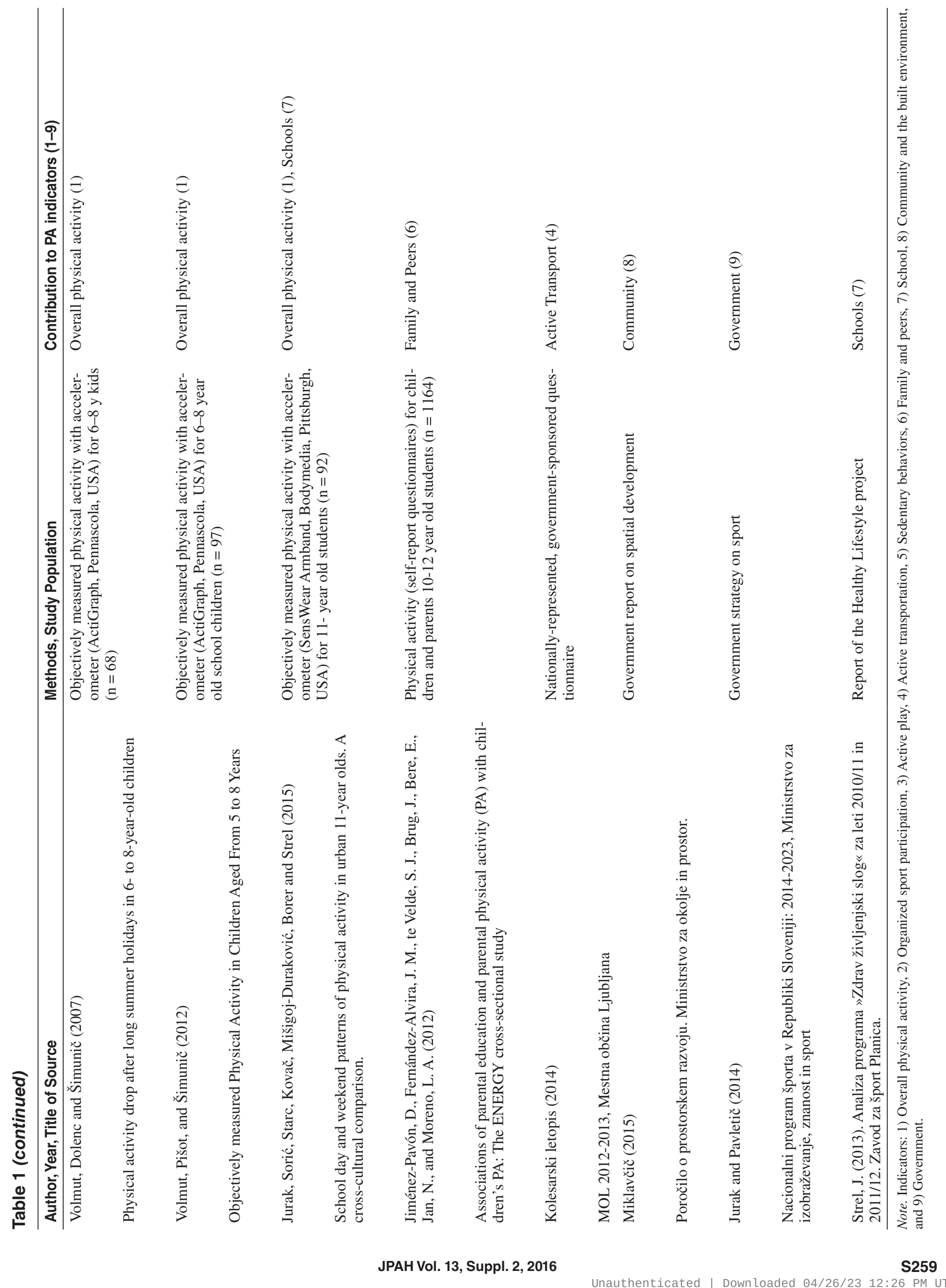


Table 2 Grades According to Physical Activity Indicators in the 2016 Republic of Slovenia Physical Activity Report Card for Children and Youth

\begin{tabular}{lc}
\hline Indicator & Grades \\
\hline Overall Physical Activity Levels & $A-$ \\
Organized Sport Participation & $B-$ \\
Active Play & $D$ \\
Active Transportation & $C$ \\
Sedentary Behaviors & $B+$ \\
Family and Peers & $I N C$ \\
Schools & $A$ \\
Community and the Built Environment & $I N C$ \\
Government Strategies and Investments & $B+$ \\
\hline
\end{tabular}

Note. The grade for each indicator is based on the percentage of children and youth meeting a defined benchmark: $A$ is $81 \%$ to $100 \%$; $B$ is $61 \%$ to $80 \%$; $C$ is $41 \%$ to $60 \%, D$ is $21 \%$ to $40 \% ; F$ is $0 \%$ to $20 \%$; INC is Incomplete data.
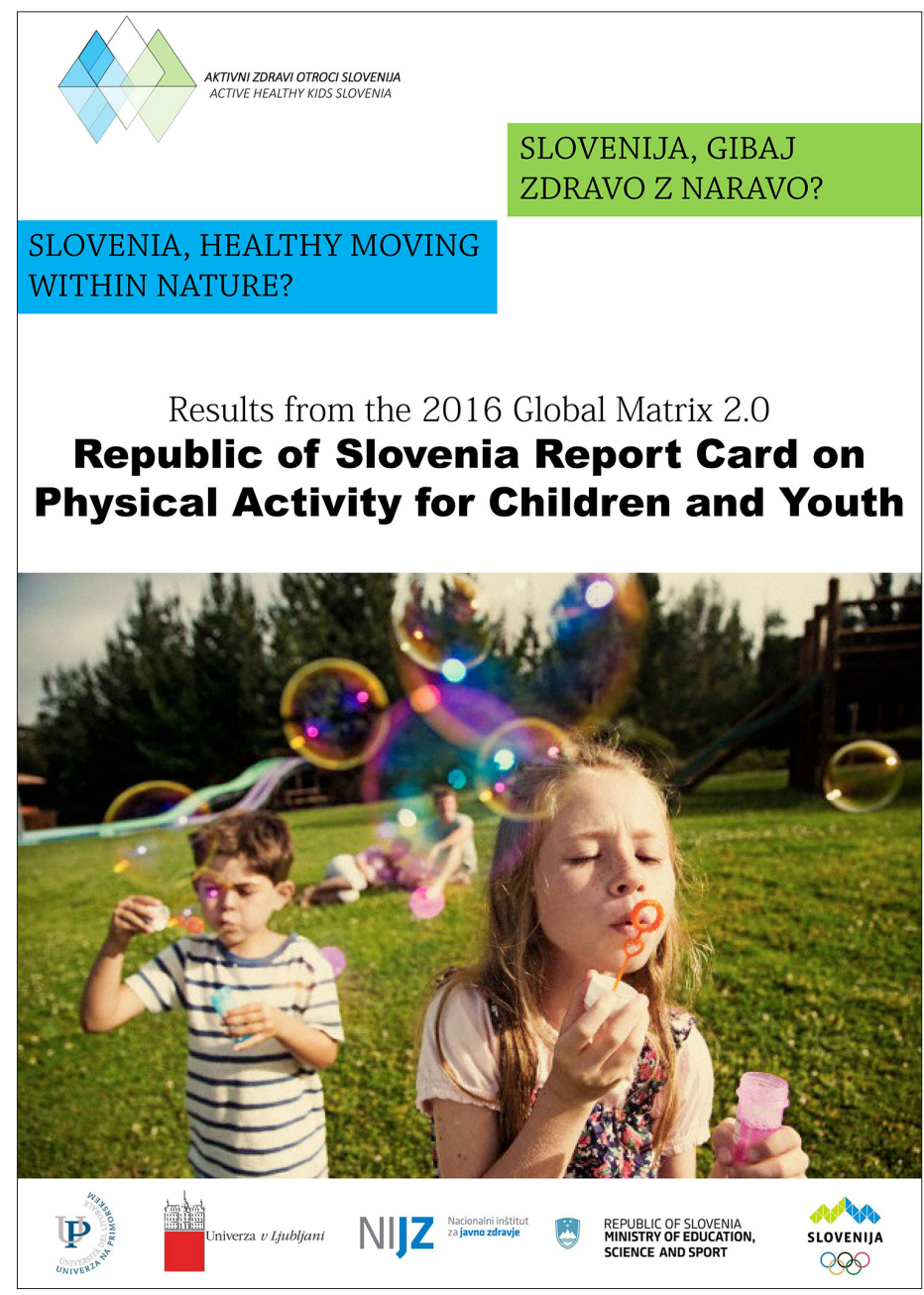

Figure 1 - Front cover of the 2016 Republic of Slovenia Physical Activity Report Card for Children and Youth. to bike: bike $43 \%$; walk $28 \%$; car $20 \%$; bus/train $9 \%$. The ACDSi data $^{9,10}(\mathrm{~N}=5207)$ indicates that active commuting to school remains relatively stable with age, with $\sim 52 \%$ of boys and $\sim 50 \%$ girls from age 5 to 18 years actively commuting to school. Active transportation was graded $C$.

\section{Sedentary Behaviors: $B+$}

Data on combined screen time (computer, gaming, internet, mobile phone use) during weekdays and weekends was assessed by the ACDSi study ${ }^{9,10}$ using the CLASS ${ }^{12}$ and SHAPES ${ }^{13}$ questionnaires, and by the HBSC 2014 data (in children aged 11, 13, 15 y). The HBSC study in Slovenia (which includes only 3 age-groups: 11-, 13-, and 15-year-olds), indicates that during weekdays, 53\% of these age-groups watch television more than 2 hours per day, and $28 \%$ play computer games more than 2 hours each day. Unfortunately, the HBSC study does not provide information on total screen time; further, these results differ significantly from those obtained in the ACDSi study. Specifically, daily screen time (calculated as a sum of TV watching, computer gaming, and web surfing shows) during school days indicate that $90 \%$ of boys and girls meet the recommendation of less than 2 hours of screen time per day. During weekends this percentage decreases to $37 \%$ and $45 \%$ of boys and girls, respectively. Overall, $74 \%$ of boys and $79 \%$ of girls aged 6 to 19 years meet the recommendations for screen time. Thus, for 5 days of the week, children are in an $A+$ range, whereas on weekends this drops to a $\sim C$. Sedentary behaviors was graded a $B+$ overall.

\section{Family and Peers-Infrastructure, Support, Parental/Peer Behaviors: INC}

The evidence on family- and peer-related encouragement of PA in Slovenia is scarce. The ACDSi study finds that more than $75 \%$ of parents encourage their children between 11 and 19 years to be physically active. Almost $90 \%$ of parents indicate they support opportunities for PA by buying sports equipment, driving kids to practice, etc. When asked about their parent's PA levels, children perceived their fathers to be 'very active' in $~ 30 \%$ of cases and 'moderately active' in $35 \%$ of cases. They perceived mothers' physical activity to be $21 \%$ for 'very active' and $~ 40 \%$ for 'moderately active' rankings, similar to $47 \%$ of active Slovenian parents. ${ }^{16}$ Regarding peer support for PA, the ACDSi study found that among children who perceive themselves to be physically active, peer support is higher in boys than girls. In boys, $64 \%$ reported having more than 4 friends who are physically active, whereas only $38 \%$ of physically active girls reported having more than 4 physically active friends. Family and peers was graded INC overall.

\section{Schools-Infrastructure, Policies, and Programs: $A$}

In Slovenia, physical education (PE) is a compulsory subject in all primary and secondary schools and each school follows the same PE curriculum. PE minutes vary by grade such that primary schools (grades 1 to 5) receive a minimum of 105 hours per year, grades 7 to 8 receive 70 hours per year, and grade 9 receives 62 hours per year. Grades 7 to 9 have opportunities to select an additional 35 hours of elective sport classes and 35 hours of elective dance classes. Grades 4 to 6 may also select an additional 35 hours of elective, health-oriented sport classes. ${ }^{17}$ In addition to regular PE classes, primary school children have 5 sport days in each grade, each lasting 5 hours, adding an additional 25 hours of school-based PA in a 
school year. Some primary schools in Slovenia organize enhanced $\mathrm{PE}$ curriculum, during which children receive supplementary lessons. ${ }^{18}$ Additionally, primary schools in Slovenia are allowed to have more than the prescribed minimum of 2 or $3 \mathrm{PE}$ lessons per week if the school board decides so, although less than $10 \%$ of schools actually do. All primary schools are obliged to offer extracurricular sport programs, which are free of charge for all children. In the best case scenario, a 10-year-old in Slovenia can receive 131 hours (or 7875 minutes) of regular PE lessons, plus 25 hours in school sport days, 35 hours of elective sport courses, and at least 35 hours of extracurricular school-based sport practice, summing to a total of 226 hours of school-based PE. Thus, Slovenian primary schools offer access to $77 \mathrm{~min}$ of daily in-school, professionally guided PA. In the (worst-case) example a 10-year-old would participate in only the compulsory 3 weekly lessons of PE and obligatory school days, which equates to $\sim 39$ min per school day-still more than half the 60 min of recommended daily PA.

In secondary schools, the number of PE lessons vary according to the type of school and grade. Most secondary students have 3 hours of PE per week, some have 2 hours, and some vocational programs provide only $1 \mathrm{PE}$ lesson per week. Certain grammar schools also have sport classes which account for 6 hours of PE per week. ${ }^{19}$ Secondary schools also organize special sport days, but they are not obliged to organize extracurricular sport programs like primary schools.

The percentage of PE classes taught by a specialist vary by grade, such that from grades 1 to $5, \mathrm{PE}$ is generally taught by a standard classroom teacher; in grades in 1 to $3,15 \%$ of classrooms have a specialist PE teacher; in grades 4 to 5, 50\% are specialists; and from grade 6 through secondary school, 100\% of PE classes (and more than two-thirds in primary schools) are taught by PE teachers with a university degree. ${ }^{20}$ Finally, regarding school sports infrastructure, Slovenia is very developed because every primary school and most secondary schools have at least 1 sport hall (most have 2) that is fully equipped with all necessary sports equipment and additional outdoor facilities. ${ }^{21}$ All schools in Slovenia have PA school policies (eg, bike racks at school, traffic calming on school property, outdoor time). Schools, infrastructure, policies, and programs was graded $A$ overall.

\section{Community and the Built Environment- Infrastructure, Policies, Programs, Safety: INC}

Slovenia is among the least urbanized EU countries, with an urbanization rate of $\sim 50 \%$. It has a characteristic settlement pattern of dispersed small settlements and strong trends of suburbanization and peri-urbanization, with settlement development along transport corridors and a prevailing housing typology of single family houses. The overall consequence is an increase in commuters and difficulty organizing public transport. ${ }^{22}$ Private cars prevail in passenger transport; indeed, car ownership effectively doubled in the past 20 years to a rate of 500 per 1000 inhabitants. ${ }^{22}$ In cities, densification of urban structure has led to excessively high usage of building plots and a reduction of open green spaces, decreasing urban housing quality. ${ }^{23}$

Municipalities are, on the one hand, building bicycle lanes, walking paths, etc., but there seems to be a lack of a uniform strategy to plan urban environments, especially regarding maximizing PA opportunities. Sport infrastructure, the natural environment, and parks are often within walking distance in urban centers, but these spaces are not always accessible to children because of motor traffic that crosses walking paths. The ACDSi study included only
1 question that could be related to the built environment. When 11- to 14-year-olds were asked why they don't walk to school, only $10 \%$ considered it unsafe to walk. Overall, the empirical data on the influence of the built environment on PA in Slovenia are scarce. Therefore, this category was graded INC.

\section{Government-Strategies, Policies, Investments: $B+$}

The Slovenian Parliament has adopted a National Program of Sport 2014-2023. ${ }^{24}$ One year later it also adopted the National Program of Nutrition and Physical Activity for Health 2015-2025. ${ }^{25}$ For the first time in the history of an independent Slovenia, the latter program coordinates the efforts of public health, sport, and the educational sector, emphasizing PA, along with nutrition, as key factors in achieving public health goals. Both strategies encourage the entire Slovenian population (from children to elderly) to adopt healthy lifestyles. These initiatives will provide the foundations for implementing publicly funded, high-quality, organized PA programs on both national and local levels. These programs especially focus on raising the quality and quantity of PA in children and youth, with additional emphasis on socially underprivileged groups. The National Program of Sport 2014-2023 proposes the following (noninclusive) actions: to provide at least $180 \mathrm{~min}$ of high quality PE per week to every child to develop habitual PA and a healthy lifestyle, to provide free swimming and cycling lessons as a means of enhancing social competencies, and to ensuring leisure time for sporting activities. ${ }^{24}$

In the past 2 decades, the national government and municipalities have invested in the reconstruction of old, and the building of new, school sport halls including other sport infrastructure. For example, from 2001 to 2008 public funding of sport infrastructure exceeded $€ 300$ million. ${ }^{26}$ The policy of the Ministry of Education, Science, and Sport also enforces rules related to the professional competencies of teachers and trainers in PE and youth sport, which require people to have a university degree in $\mathrm{PE}$ to work with young athletes. ${ }^{27}$ In addition, the Ministry currently develops strategies to implement compulsory, joint teaching of regular classroom teachers and PE teachers within the first 5 years of primary school to raise the quality and effectiveness of PE. Finally, more than 25 years ago, the government of Slovenia established the Centre for School and Outdoor Education program, which has 23 learning centers scattered throughout the country. Each of these centers employs at least $1 \mathrm{PE}$ specialist and offers various outdoor activities that are not available within regular school settings.

A key reason for the past effectiveness of government policies related to schools, sport infrastructure, $\mathrm{PE}$, and its curriculum in Slovenia is the evidence-based policy planning of the Ministry of Education, Science, and Sports. ${ }^{17}$ The Ministry has continuously supported the SLOfit monitoring system and has been using evidence of secular trends in physical and motor development of children and youth to plan its future activities and interventions, as well as evaluate their effectiveness. To wit, the Ministry introduced a health-oriented PA intervention program, Healthy Lifestyle, to combat growing childhood obesity and declining physical fitness. ${ }^{2}$ Current evidence from SLOfit data suggests that these state-wide interventions are effective at influencing population movements, ${ }^{2}$ because obesity trends have been in decline since 2011 and the physical fitness of primary school children has improved significantly. ${ }^{2}$ Government strategies, policies, and investments was graded $B+$ 


\section{Discussion}

Physical activity levels among children and youth in Slovenia are high compared with other nations, despite concurrently high sedentary behaviors recorded during weekdays and weekends. According to national ACDSi and smaller-sample local data, ${ }^{6,15}$ the majority of children (ages 6 to $18 \mathrm{y}$ ) meet the recommendations of 60 min of moderate-to-vigorous PA per day. Indeed, all schools in Slovenia offer PA opportunities to their students, and the majority of Slovenian students are physically active for at least $200 \mathrm{~min}$ per week during school days. Considering the very good conditions for overall PA, PE, and the extracurricular sports programs on offer in the school system, free-time outdoor play is lagging behind, since only $30 \%$ (or less) of Slovenian children and youth report actively playing (eg, includes playing in the house yard, roller-skating outside, playing catch, riding bike, etc.) more than 2 hours per day. It appears that organized PA is dominating children's everyday life in Slovenia, but is not equally accompanied by spontaneous outdoor play in their free-time, possibly due to increased weekend screen times. During weekends when children do have time to play outdoors, sedentary behaviors increase and seem to neutralize the potential of outdoor play.

In previously published AHKGA reports, other European countries graded overall PA with lower grades, including $D$ (Finland $^{28}$ and Ireland $\left.{ }^{29}\right), C / D$ England $\left.^{30}\right)$ and $D$ - $\left(\right.$ Scotland $\left.^{31}\right)$. Current data on trends in PA are often scarce, and those which do exist are commonly reported from higher-income countries. ${ }^{32}$ Nevertheless, although children in Slovenia meet all PA international recommendations, they could improve on being more active during weekends. ${ }^{15,33}$ Slovenia has very well-organized educational and sports systems; however, this over-reliance on structured support may lead to underdeveloped competencies for self-organized spontaneous play in children. Organized PA in the form of PE, extracurricular sports programs, and club-based sports participation are also oriented toward the use of indoor sports facilities, and in this sense, may inadvertently educate children to perceive PA mostly as activity linked to sports infrastructure and organized play. Schools should especially be encouraged to increase the use of their natural environment on daily a basis, while parents should be educated that school PE, extracurricular activities, and sports training account only for a portion of children's overall PA, and that they too should put more effort into lowering sedentary time and increasing active play time in home-settings. Indeed, the majority of countries included in Global Matrix 2014 program graded Active Play with a $D$ or $I N C$, highlighting that this aspect of children's development does not currently receive enough research or policy attention. Slovenia is no exception to this trend. Certainly there is a role for more government initiatives which promote active outdoor play and family-based free-time PA.

Urbanization, mechanization, and an increased use of motorized transport are changing PA levels globally. ${ }^{34}$ Although bicycle infrastructure has improved, especially in the larger centers [eg, Ljubljana's very successful free bike rental Bicike(LJ)], only a little more than one-half of all school children (52\% of boys and 50\% of girls from age 6 to $19 \mathrm{y}$ ) actively commute to school. Governmental policies are not currently directed toward increasing active transport in the child and youth populations, although there are nongovernmental organizations such as the Institute for Spatial Policies (www. ipop.si/en/) which do organize project initiatives. One such program is Healthy Pupil, which encourages active commuting to school via "a walking bus" or "bike-train," providing increased safety for children traveling in groups. Active transportation for Slovenia was graded a $C$, like Scotland in 2014. ${ }^{31}$

Finally, many childhood health-enhancing policies call for children to be physically active daily, to limit screen-time, and to increase active play. Slovenia is also witnessing an imbalance regarding lower active play and higher screen-times during weekends, when families decide what to do with their free time. More effort is required to maximize the use of existing resources, increase outdoor, active play and family-child centered PA, while at the same time further increasing PA opportunities in the community. An emphasis on improving free-time outdoor play opportunities and accessibility to natural environments is essential for Slovenia to address in future nation-wide interventions.

\section{Strengths and Limitations}

Undoubtedly, one of the strengths gleaned from this research is the robust state of PE currently in place within the primary and secondary school systems of the Republic of Slovenia. Objectively measured evidence confirms children and youth have the opportunity to, and engage in, appropriate levels of weekly PA minutes over the standard school week. Annual data collection for child and youth physical fitness provided strong evidence-based data to support many indicators. In addition, the diverse background of the members of the RWG were a strength to the research, which included representation of members from the National Institute of Public Health; Ministry of Education, Science, and Sport; Slovenian Olympic Committee; a Headmaster of an elementary school; researchers and professors from the field of physical activity, physical education, organized sport, and landscape architecture; and a medical doctor. The Report Card used a standardized rubric to grade all indicators, which will aid in international comparisons and identify temporal trends within the country.

Although grades are based on the best available data, there were significant research gaps, especially for family and peers, as well as community, which precluded proper grade assignment.

\section{Conclusions}

PA levels are generally well-maintained in Slovenian school-aged children, especially during the weekdays, demonstrating that wellestablished school-based activities (such as PE curriculum, SLOfit, HLS) can provide appropriate measures to deal with physical inactivity. Thus, it remains a priority to maintain attention on PA policy makers to continue robust, national PA programs. In Slovenia, sedentary behavior is higher on weekends and during holidays when kids are outside the structured school system. There is a need for further research investigating the effects of family life and peer influences on PA behavior, including more research initiatives into quantifying the effects of outdoor/active play behaviors. Currently, Slovenia is not giving enough consideration to the built environment, or supporting active transport and free outdoor play.

\section{Acknowledgments}

The authors thank the following members of the Active Health Kids Slovenia Research Work Group for their contributions to the 2016 Report Card: Mojca Gabrijelčič, National Institute of Public Health, Tjaša Kotar, Ministry of Education, Science and Sport, Janet Klara Djomba, University of Ljubljana, Faculty of Medicine, Primož Kotnik, Paediatric Hospital of Ljubljana and Marko Primožič, Headmaster of Ivan Grohar Primary School. 
This work was supported by internal funding from the Bio-Psycho-Social Contexts of Kinesiology Research Group of the Faculty of Sport.

\section{References}

1. Statistical Office of the Republic of Slovenia. Statistical Yearbook of Slovenia 2000-2011. Ljubljana: Statistical Office of the Republic of Slovenia; 2011.

2. Strel J. Analiza programa »Zdrav življenjski slog« za leti 2010/11 in 2011/12. [Analysis of the program Healthy Lifestyle for the years 2010/11 and 2011/12]. Ljubljana: Institute for Sport Planica; 2013.

3. Jeriček-Klanšček H, Koprivnikar H, Drev A, Pucelj V, Zupanič T, Britovšek KZ. Z zdravjem povezana vedenja $v$ šolskem obdobju med mladostniki v Sloveniji: Izsledki mednarodne raziskave HBSC, 2014. [Health-related behavior in school-aged children and adolescents in Slovenia: Results of an International Survey HBSC, 2014]. Ljubljana: National Institute for Public Health; 2015.

4. Volmut T, Dolenc P, Šimunič B. Physical activity drop after long summer holidays in 5- to 8-year old children. In: Exercise and Quality of life 2008. Novi Sad: Faculty of Sport and Physical Education Novi Sad; 2008:75-82. http://www.eqol.uns.ac.rs/1steqol/1\%20children/013\%20volmut\%20dolenc\%20simunic.pdf. Accessed February $15,2016$.

5. Kropej VL, Videmšek M, Pišot R. Relationship between sports activity, smoking and alcohol and marijuana abuse in elementary school children in Slovenia. Acta Univ Palacki Olomuc Fac Med. 2008;38:7-15.

6. Volmut T, Pišot R, Šimunič B. Objectively measured physical activity in children aged from 5 to 8 years. Slovenian Journal of Public Health. 2013;52(1):9-18. doi:10.2478/sjph-2013-0002

7. Pušnik T, Volmut T, Šimunič B. The quantity and intensity of physical activity during physical education in 3rd grade primary school children. Annales Kinesiologiae. 2015;5(2):123-130.

8. Strel J. Sports Educational Chart. Ljubljana: Ministry of Education and Sport; 1997.

9. Jurak G, Kovač M, Starc G. The ACDSi 2013-The Analysis of Children's Development in Slovenia 2013: Study protocol. Anthropol Noteb. 2013;19(3):123-143.

10. Starc G, Kovač M, Strel J, et al. The ACDSi 2014—a decennial study on adolescents' somatic, motor, psycho-social development and healthy lifestyle: study protocol. Anthropol Noteb. 2015;21(3):107123.

11. Colley RC, Brownrigg M, Tremblay MS. A model of knowledge translation in health: the Active Healthy Kids Canada Report Card on physical activity for children and youth. Health Promot Pract. 2012;13(3):320330. PubMed doi:10.1177/1524839911432929

12. Telford A, Salmon J, Jolley D, Crawford D. Reliability and validity of physical activity questionnaires for children: The Children's Leisure Activities Study Survey (CLASS). Pediatr Exerc Sci. 2004;16:64-78. doi:10.1123/pes.16.1.64

13. Leatherdale ST, Manske S, Wong SL, Cameron R. Integrating research, policy, and practice in school-based physical activity prevention programming: the School Health Action, Planning, and Evaluation System (SHAPES) Physical Activity Module. Health Promot Pract. 2009;10(2):254-261. PubMed doi:10.1177/1524839906298499

14. Maddison R, Dale LP, Marsh S, LeBlanc AG, Oliver M. Results from New Zealand's 2014 Report Card on Physical Activity for Children and Youth. J Phys Act Health. 2014;11(Suppl 1):S83-87. PubMed doi:10.1123/jpah.2014-0180

15. Jurak G, Sorić M, Starc G, et al. School day and weekend patterns of physical activity in urban 11-year-olds: a cross-cultural com- parison. Am J Hum Biol. 2015;27(2):192-200. PubMed doi:10.1002/ ajhb. 22637

16. Jiménez-Pavon D, Fernández-Alvira JM, te Velde SJ, et al. Associations of parental education and parental physical activity (PA) with children's PA: The ENERGY cross-sectional study. Prev Med. 2012;55(4):310-314. PubMed doi:10.1016/j.ypmed.2012.07.011

17. Kovač M, Strel J, Jurak G, Starc G. The importance of research-based data for design of intervention sport programmes for children. In: Zbornik radova; istraživanja paradigm djetinstva, odgoja I obrazovanja. [Book of selected papers: researching paradigms of childhood education]. Zagreb: Faculty of Teacher Education; 2015:1-11.

18. Jurak G, Cooper A, Leskošek B, Kovač M. Long-term effects of 4-year longitudinal school-based physical activity intervention on the physical fitness of children and youth during 7-year follow-up assessment. Cent Eur J Public Health. 2013;21(4):190-194. PubMed

19. Zupančič M, Justin J. The Slovene model of sports classes in grammar schools: psychological and educational point of view. Educ Res Eval. 1998;4(1):42-56. doi:10.1076/edre.4.1.42.13012

20. Kovač M, Jurak G, Starc G, Strel J. The Importance of Research-based Evidence for Political Decisions on Physical Education. In: Hardman, K, Green K, ed. Contemporary Issues in Physical Education: International Perspectives. Maidenhead, UK: Meyer \& Meyer Sport; 2011:47-68.

21. Jurak G, Leskošek B, Strel J. Prostorska razpršenost in starost šolskih športnih dvoran ter skupine njihovih uporabnikov. [Geographically dispersion and age of sports halls and a group of its users]. Šport. 2013;61(3-4):130-138. [Sport].

22. Miklavčič T. Poročilo o prostorskem razvoju. [Report of Spatial Development].Ljubljana: Ministry of the Environment and Spatial Planning; 2014.

23. Simoneti M, Nared PV. Analiza Večstanovanjske Gradnje v Ljubljani. In: Stanovanjske Krajine, Trendi in Perspektive. [Residential Landscape, Trends and Perspectives].Ljubljana: Biotechnical Faculty; 2006.

24. Jurak G, Pavletič P. Nacionalni program športa v Republiki Sloveniji: 2014-2023. [National Sport program in the Republic of Slovenia: 2014-2023]. Ljubljana: Institute of sport Planica; 2014.

25. Ministry of Health Slovenia. Resolucija o nacionalnem programu. [Resolution on National Programme on Nutrition and Physical Activity for Health]. Ljubljana: Ministry of Health Slovenia; 2015.

26. Jurak G. Analiza šolskega športnega prostora s smernicami za nadaljnje investicije: Zaključno poročilo. [Analysis of School Sport Area with guidelines for further investments: Final report]. Ljubljana: Faculty of Sports; 2012.

27. Ministry of Education. Science and Sports. Zakon o športu. [Law of sports]. Ljubljana: Uradni list RS; 1998. http://www.uradni-list.si/1/ objava.jsp?urlid=199822\&stevilka=929.

28. Liukkonen J, Jaakkola T, Kokko S, et al. Results from Finland's 2014 report card on physical activity for children and youth. $J$ Phys Act Health. 2014;11(Suppl 1):S51-57. PubMed doi:10.1123/jpah.20140168

29. Harrington DM, Belton S, Coppinger T, et al. Results from Ireland's 2014 Report Card on Physical Activity in Children and Youth. $J$ Phys Act Health. 2014;11(Suppl 1):S63-68. PubMed doi:10.1123/ jpah.2014-0166

30. Draper C, Basset S, De villiers A, Lambert EV, et al. Results from South Africa's 2014 Report Card on Physical Activity for Children and Youth. J Phys Act Health. 2014;11(Suppl 1):S98-104. PubMed doi:10.1123/jpah.2014-0185

31. Reilly J, Dick S, McNeill G, Tremblay MS. Results from Scotland's 2013 report card on physical activity for children and youth. J Phys Act 
Health. 2014;11(Suppl 1):S93-97. PubMed doi:10.1123/jpah.20140183

32. Hallal PC, Andersen LB, Bull FC, et al. Global physical activity levels: surveillance progress, pitfalls, and prospects. Lancet. 2012;380(9838):247-257. PubMed doi:10.1016/S0140-6736 (12)60646-1

33. Kovač M, Strel J, Jurak G, et al. Physical Activity, Physical Fitness Levels, Daily Energy Intake and Some Eating Habits of 11-Year-Old
Children. Hrvatski časopis za odgoj i obrazovanje. [Croatian Journal of Education]. 2013;15(1):127-139.

34. Sullivan R, Kinra S, Ekelund U, et al. Socio-demographic patterning of physical activity across migrant groups in India: results from the Indian Migration Study. PLoS One. 2011;6e24898 doi:10.1371/ journal.pone. 0024898 